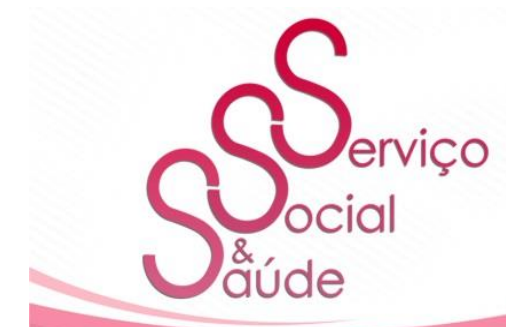

ISSN 2446-5992

(c) 10 (2)

doi: 10.20396/sss.v19i0.8665362

\title{
Estresse ocupacional e os impactos na saúde das assistentes sociais de uma Unidade Hospitalar de atendimento à criança em Boa Vista - Roraima'
}

\section{Occupational stress and the impacts on health of Social Workers in a child care Hospital Unit in Boa Vista - Roraima}

Tatianne Lorenna Vieira Medeiros ${ }^{2}$

Kesy Stheffany Silva Lopes ${ }^{3}$

Janaine Voltolini de Oliveira ${ }^{4}$

\section{RESUMO}

O objetivo deste estudo é discutir a atuação profissional de assistentes sociais no contexto de uma unidade hospitalar de atendimento à criança em Boa Vista - Roraima, e os impactos do trabalho na saúde mental destas profissionais, em específico, do estresse ocupacional. Idealizada a partir das vivências em campo durante o ano de 2019, nas disciplinas de Estágio Supervisionado em Serviço Social I e II, a pesquisa, de abordagem mista, realizada com base em revisão bibliográfica, pesquisaação e entrevistas a partir de questionários com 18 profissionais, possibilitou, além da observação da realidade institucional e do fazer profissional, o revisitar de conteúdos e a reflexão, por parte das profissionais, sobre o mundo do trabalho, as demandas cotidianas e sua relação com a saúde mental.

\footnotetext{
${ }^{1} \mathrm{O}$ estudo é resultado de Trabalho de Conclusão de Curso, tem aprovação do Comitê de Ética em Pesquisa CEP, da Universidade Estadual de Roraima - UERR - Parecer nº 4.148.051.

${ }^{2}$ Graduada em Serviço Social pela Universidade Estadual de Roraima (UERR). Telefone: 5595 99152-0951. Email: tatiannelorenna@ hotmail.com.br

${ }^{3}$ Assistente Social na Gerência de Apoio Pedagógico e Psicossocial da Secretaria Municipal de Educação e Cultura de Boa Vista, Roraima. Mestranda no Programa de Pós-Graduação Sociedade e Fronteiras da Universidade Federal de Roraima (UFRR). E-mail: kesystheffany13@gmail.com

${ }^{4}$ Doutora em Geografia pela Universidade Federal do Ceará (UFC) e mestre em Políticas Públicas pela Universidade Federal do Maranhão (UFMA). Docente do Curso de Serviço Social da Universidade Estadual de Roraima (UERR) e Assistente Social do Tribunal de Justiça de Roraima (TJRR). Cursando Estágio Pós-doutoral no Centro Interdisciplinar de Ciências Sociais (CICS) da Universidade Nova de Lisboa, Portugal. E-mail: jjanaine.voltolini@gmail.com
} 


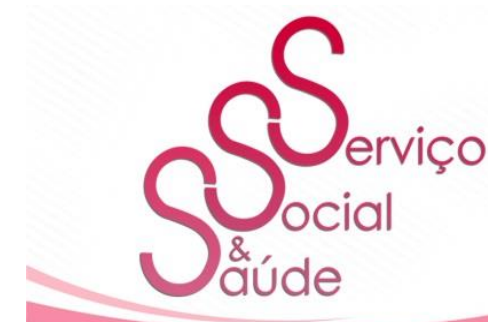

ISSN 2446-5992

(c) $10(2)$

doi: 10.20396/sss.v19i0.8665362

PALAVRAS-CHAVE: Estresse Ocupacional. Prevenção. Saúde Mental. Serviço Social.

\begin{abstract}
The aim of this study is to discuss the professional performance of social workers in the context of a hospital care unit for children in Boa Vista-Roraima, and the impacts of work on the mental health of these professionals, specifically, from occupational stress. Conceived from experiences in the field during 2019, in the subjects of Supervised Internship in Social Work I and II, the research, mixed approach, carried out based on bibliographic review, action research and interviews based on questionnaires with 18 professionals, made possible, in addition to observing the institutional reality and doing professional activities, revisiting content and reflecting, on part of professionals, about the world of work, daily demands and their relationship with mental health.
\end{abstract}

KEYWORDS: Occupational Stress. Prevention. Mental Health. Social Work.

\title{
Introdução
}

As recentes transformações tecnológicas, econômicas, sociais, políticas e científicas que compõem a realidade da sociedade global trouxeram mudanças significativas na forma de organizar e gerir os diversos processos de trabalho e impactam, direta ou indiretamente, aspectos da vida da classe trabalhadora, sobretudo, na saúde do trabalhador - elemento central desta análise.

Essas transformações, assim como afirmam Reis, Fernandes e Gomes (2010), trazem uma nova perspectiva de trabalho: mais intelectualizado, mais "enxuto", envolto pelas redes de computadores e que, contraditoriamente, não proporcionam melhores condições de trabalho, mas sim novas formas de exploração com implicações fisiológicas, emocionais e psicológicas para a saúde da classe que vive do trabalho.

Os impactos dessas transformações apresentam características que levam cada vez mais o trabalhador à fadiga, a exemplo da intensificação das atividades, do aumento de tarefas com redução do tempo de resposta à tomada de decisões, do medo do desemprego e da substituição do trabalho do homem pelas máquinas, entre outros. Todo esse contexto surge a 


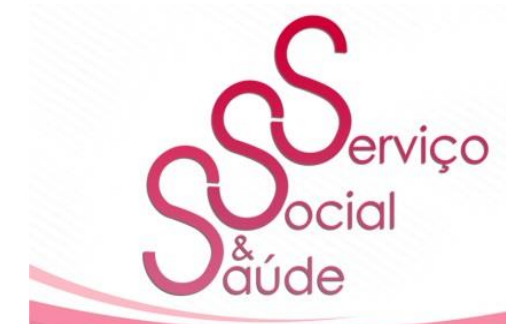

ISSN 2446-5992

$\Theta \odot \Theta \odot$

doi: $10.20396 /$ sss.v19i0.8665362

partir da assertiva da flexibilização do trabalho e de uma pseudo facilidade produtiva eficiente.

Para melhor situar o objeto da análise, a discussão volta-se para o estresse ocupacional como fator determinante para a qualidade da saúde do trabalhador, uma vez que este apresenta, segundo Reis, Fernandes e Gomes (2010, p. 715), “[...] consequências fisiológicas, psicológicas e comportamentais que são mediadas pela percepção, com foco na susceptibilidade do indivíduo [...]" e cuja ação na perspectiva preventiva no ambiente de trabalho pode tornar a atividade não-prejudicial à saúde do trabalhador, numa compreensão de que as condições objetivas e subjetivas da realização laboral influenciam diretamente na qualidade de vida dos profissionais.

Como uma das bases para a elaboração deste estudo, a Política Nacional de Saúde do Trabalhador e da Trabalhadora, instituída pela Portaria $\mathrm{n}^{\mathrm{o}} 1.823 / 2012$, dispõe, no art. $8^{\circ}$, inciso V sobre "incorporar a categoria trabalho como determinante do processo saúde-doença dos indivíduos e da coletividade, incluindo-a nas análises de situação de saúde e nas ações de promoção em saúde". Deste modo, se apreende que a própria legislação sinaliza sobre a importância dessa abordagem e institui a saúde como um direito do trabalhador.

Sobre as ações de saúde, o art. $3^{\circ}$ da Lei 8.080/1990 ressalta que "se destinam a garantir às pessoas e à coletividade, condições de bem-estar físico, mental e social”, deixando claro que esta não se caracteriza apenas como ausência de doença, mas também como condições adequadas para a promoção do bem-estar social, mental e físico.

A escolha pela abordagem da temática surgiu a partir de observações e intervenções realizadas durante os Estágios Supervisionados em Serviço Social I e II, com profissionais de uma unidade de saúde de alta complexidade de atendimento à criança, onde foi possível compreender a realidade institucional da unidade hospitalar, a cotidianidade do fazer profissional das assistentes sociais, as expressões da questão social apresentadas em forma de demandas e suas estratégias de intervenção, a instrumentalidade e os impactos das novas formas de trabalho na atuação profissional interprofissional, multiprofissional e em 


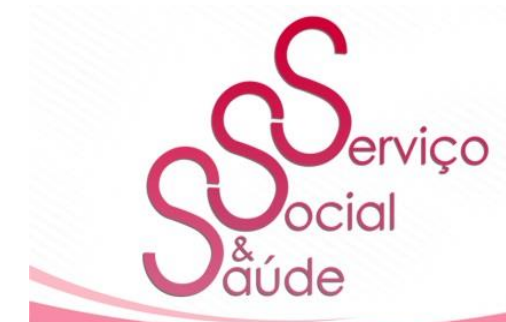

ISSN 2446-5992

(c) $10(2)$

doi: 10.20396/sss.v19i0.8665362

articulação com a rede e a relação destes e outros elementos com o autocuidado, o adoecimento e a saúde das trabalhadoras.

Portanto, longe de criar uma conjuntura utópica e mistificadora sobre a eliminação das fontes de estresse, o que se buscou durante a revisão bibliográfica que subsidiou a definição do problema de pesquisa, das hipóteses levantadas no período de observação e aplicação de questionário de entrevistas, foi discutir sobre esses elementos e construir alternativas de enfrentamento ao estresse, mesmo envolto nas vivências cotidianas do fazer profissional. Isto porque, milhares de trabalhadores no mundo se encontram em situação de adoecimento em razão do trabalho.

\section{Trabalho e adoecimento}

$\mathrm{Na}$ contemporaneidade, as formas de ser do trabalho têm sofrido diversas modificações, seja a partir da revolução tecnológica, seja pela era informacional, seja pela mecanização do trabalho ou pela corrida desenvolvimentista que se instalou na cotidianidade da humanidade. O fato que se apresenta é a intensificação e heterogeneização dos processos de trabalho, transformações estas que, de algum modo, direta ou indiretamente, incidiram sobre a vida dos trabalhadores.

Segundo Antunes (2015, p. 114), “[...] as diversas manifestações de estranhamento atingiram, além do espaço da produção, ainda mais intensamente a esfera do consumo, a esfera da vida fora do trabalho [...]". Para o autor, o sistema sociopolítico capitalista adentrou em todos os aspectos da vida da classe que vive do trabalho. Seja na esfera da produção ou na esfera da vida particular, a classe trabalhadora sofre as influências ideológicas, políticas e sociais do sistema vigente.

Endossando este entendimento, Reis, Fernandes e Gomes (2010) afirmam que:

As transformações econômicas, tecnológicas e institucionais que vêm ocorrendo, principalmente nas três últimas décadas, têm impactado profundamente a forma de gerir as organizações, inclusive no que diz respeito à gestão de pessoas. Tais mudanças têm gerado repercussões diferenciadas na saúde e na integridade do trabalhador. Para sobreviver, as 


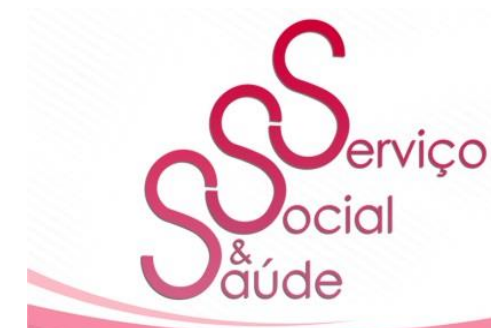

ISSN 2446-5992

(๑) $(0)$

doi: $10.20396 /$ sss.v19i0.8665362

organizações desenvolvem um novo patamar organizacional coerente com o seu novo ambiente, que se caracteriza por ser cada vez menos previsível e por apresentar crescente instabilidade; além disso, alteram sua organização do trabalho para uma estrutura que privilegia a integração e a flexibilidade, incentivando o dinamismo, a participação do trabalhador, o trabalho cooperativo e em equipe, o incremento da velocidade, a polivalência e a rotação de tarefas. Tais práticas têm como filosofia a superação constante, e visam a melhorar e a modificar sempre a organização da força de trabalho para, permanentemente, promover a evolução tecnológica e obter competitividade (ibid., 2010, p. 713).

A base de todo esse processo de flexibilização da produção de mercadorias são as constantes crises econômicas enfrentadas pelo sistema capitalista. Sob a imperiosa necessidade de reprodução em escala cada vez mais ampliada do capital, uma das saídas adotadas é a flexibilização do processo produtivo, que representa a "diluição" dos centros produtivos. Deste modo, as grandes empresas não mais centralizam todos as fases do processo, regionalizando a produção, ou seja, busca em cada parte do mundo a tecnologia necessária para a produção - tecnologia e mão-de-obra qualificada a baixo custo, matériaprima e ideias inovadoras que valorizam o capital.

Contudo, concomitante ao processo de flexibilização dos processos produtivos ocorre também a flexibilização da vida dos trabalhadores, num ataque frontal à qualidade de vida desta classe, que convive com horas exaustivas de trabalho, metas que parecem inalcançáveis e intensa (e desleal) concorrência estabelecida no seio da própria classe, o que faz com que os sujeitos não se reconheçam enquanto classe, mas sim enquanto concorrentes e até inimigos, na esteira de um sistema que mistifica e coisifica a vida.

A partir deste contexto, é possível perceber que o trabalhador é aquele sujeito que vive em situação de instabilidade. Ele é, pois, mistificado sob o pseudônimo de colaborador, deve ser polivalente, multifuncional, dinâmico e, caso não o seja, será lançado para fora do mercado de trabalho. Com todos esses fatores e sob a égide do sistema capitalista, se estabeleceu no núcleo da classe trabalhadora uma intensa disputa. $\mathrm{O}$ argumento imperioso de trabalho qualificado e especializado vem impondo à classe que vive do trabalho a necessidade voraz da busca pelo novo, pelo diferencial. Estar à frente do outro sujeito significa maiores chances em adentrar na roda frenética do mercado de trabalho.

\begin{tabular}{|l|l|l|l|l|l|r|} 
Serv. Soc. \& Saúde & Campinas, SP & v. 19 & $1-26$ & e20008 & 2020 & e-ISSN 2446-5992 \\
\hline
\end{tabular}




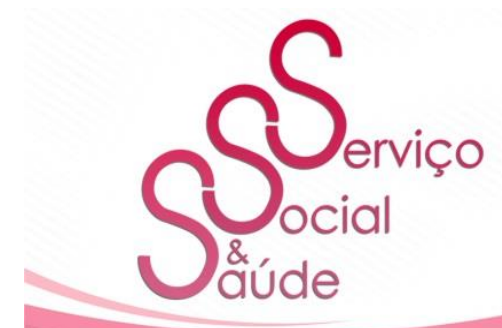

ISSN 2446-5992

(๑) $(0)$

doi: $10.20396 /$ sss.v19i0.8665362

Nesta tentativa, se buscam titulações acadêmicas, pesquisas, produções científicas e tantas outras ferramentas, através das quais é possível cultivar a esperança de sair do grupo que compõe o exército de reserva. Todavia, essa busca pelo conhecimento científico e tecnológico, do arsenal teórico-metodológico, ético-político e técnico-operativo, que funcionam como armas na busca pelo emprego ideal, podem transformar o trabalhador em refém da sua própria causa, na medida em que impõe ao sujeito a mecanização da vida de modo cada vez mais intenso e com isso o trabalhador passa a deixar em segundo plano aspectos singulares e importantes da vida fora do trabalho.

Segundo a Organização Internacional do Trabalho - OIT, cerca de 40 milhões de pessoas são afetados por problemas de saúde relacionados ao trabalho na Europa, que tem entre $50 \%$ e $60 \%$ dos dias perdidos de trabalho relacionados a esta condição, cujo estresse ocupa a segunda posição (ASSOCIAÇÃO, 2017).

No Brasil, 40\% dos trabalhadores vivenciam situações de estresse no trabalho (BRASIL, 2019). Transtornos mentais e comportamentais são a terceira causa de incapacidade para o trabalho, correspondendo a $9 \%$ da concessão de auxílio-doença e aposentadoria por invalidez (BRASIL, 2017). Episódios depressivos são a principal causa de pagamento de auxílio-doença não relacionado a acidentes de trabalho, correspondendo a $30,67 \%$ do total, seguido de outros transtornos ansiosos - $17,9 \%$ e reações ao stress grave e transtornos de adaptação, episódios depressivos e outros transtornos ansiosos causaram 79\% dos afastamentos no período de 2012 a 2016 (ASSOCIAÇÃO. 2017). Destacam-se aqui profissões como professores, policiais e trabalhadores da saúde.

Contribuem para o cenário de agravamento do adoecimento mental no âmbito do trabalho as situações de banalização da violência, como o assédio moral institucionalizado, as relações interpessoais norteadas por autoritarismo e competitividade, a demanda constante por produtividade e a desvalorização das potencialidades e subjetividades dos trabalhadores (ASSOCIAÇÃO, 2017).

Diante desses dados, apreende-se a necessidade de discutir sobre o estresse ocupacional e sua relação com os modos de ser do trabalho. A busca pela compreensão desse fenômeno se faz necessária a partir do momento em que uma grande massa de trabalhadores 


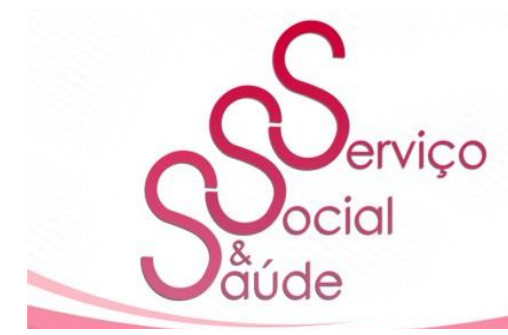

ISSN 2446-5992

(๑) $(0)$

doi: $10.20396 /$ sss.v19i0.8665362

no mundo se encontra em situação de adoecimento em razão de atividade laboral e a própria legislação sinaliza sobre a importância dessa abordagem e institui a saúde como um direito do trabalhador.

Assim, questiona-se: quais os impactos das transformações no mundo do trabalho para a saúde das assistentes sociais ${ }^{5}$, enquanto profissionais inseridas na "divisão sociotécnica do trabalho"? (RAICHELIS, 2011).

Faermann e Mello (2016, p. 97), em pesquisa sobre as implicações no processo de adoecimento de profissionais assistentes sociais, constataram que

[...] o sofrimento e o adoecimento vivenciado devem-se às suas precárias condições de trabalho, ao não reconhecimento de suas ações, à complexidade das expressões da questão social, à ineficiência das políticas públicas e aos baixos investimentos em recursos econômicos e humanos para o desenvolvimento de suas atividades. Essas situações geram sentimentos de incapacidade, angústia e mal-estar, provocando desgaste físico e mental, objetivados, muitas vezes, por meio de enfermidades e padecimentos.

Deste modo, se verifica que o trabalho da assistente social está envolto num contexto complexo de desafios que se apresentam no atendimento às demandas profissionais por meio da estrutura institucional do local de trabalho, pelas más-gestões ou pela precária existência de recursos financeiros e humanos para a execução do trabalho. Esses elementos se apresentam, muitas vezes, como condicionantes impeditivos ou que, de certa forma, limitam a ação profissional o que, ao longo do tempo, pode trazer danos para a integridade física, emocional e psicológica dos trabalhadores.

Embora todo este contexto contribua para o adoecimento dos profissionais, essas situações são vivenciadas e experimentadas de forma diferenciada por eles, tendo em vista que cada sujeito reage de forma particular a todas essas circunstâncias. Assim, para Faermann e Mello (2016, p. 100), “[...] os diversos aspectos da organização, da divisão e das relações

\footnotetext{
${ }^{5}$ A escolha por usar o gênero feminino ao se referir às/aos profissionais assistentes sociais neste trabalho se dá em razão de que $100 \%$ das entrevistas foram realizadas com trabalhadoras do gênero feminino. Sendo assim, não há nenhuma intenção em excluir o gênero masculino, mas, ao contrário, incluir e valorizar, na perspectiva de gênero, este que historicamente (numericamente) representa o Serviço Social e que possibilitou a realização da pesquisa e a supervisão dos estágios em serviço social.

\begin{tabular}{l|l|l} 
Serv. Soc. \& Saúde & Campinas, SP & v. 19
\end{tabular} 1- 26 e20008 2020 e-ISSN 2446-5992
} 


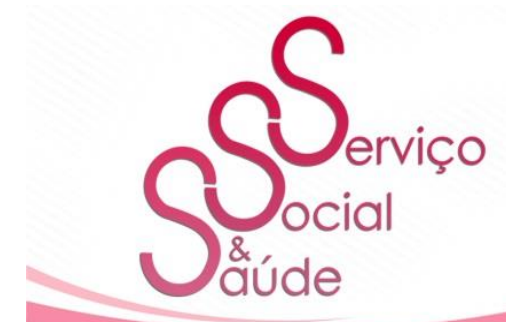

ISSN 2446-5992

(๑) $(0)$

doi: $10.20396 /$ sss.v19i0.8665362

no trabalho podem levar à fragilização ou vitalidade da saúde dos trabalhadores em diferentes realidades sociais".

Neste sentido, é possível apreender que o ambiente de trabalho, os condicionantes externos e internos, as relações interpessoais e as complexidades das demandas, interferem tanto na sua saúde como nos atendimentos que este profissional realiza. As próprias vivências e experiências pessoais carregam influenciam em suas reações mediante tais circunstâncias, o que ressalta a importância deste trabalho - tendo em vista a perspectiva de ação preventiva e de sensibilização dos profissionais em relação a sua própria saúde, no olhar para si, nos cuidados com o próprio corpo, no entendimento e na percepção de que são seres humanos e que é necessário esse "olhar para dentro" para que seja possível gozar de uma boa qualidade de vida, dentro e fora do ambiente de trabalho.

\section{O estresse ocupacional na percepção das assistentes sociais de uma Unidade Hospitalar de Atendimento à criança em Boa Vista}

Em todo o estado de Roraima, há apenas uma unidade hospitalar para atendimento a crianças com idade superior a 28 dias; do nascimento até esse período o atendimento é realizado no Hospital Materno Infantil, também a única unidade dessa natureza no estado. Sob a gestão do município de Boa Vista, capital do estado, além das crianças, são atendidos adolescentes até a idade de 16 anos e absorve a demanda da população urbana e rural, indígena e não indígena e ribeirinha dos 15 municípios de Roraima, além dos países fronteiriços: Guiana e Venezuela.

Atualmente, a unidade conta com 25 assistentes sociais que atuam na Emergência, Tratamento Fora de Domicílio - TFD, Serviço de Referência e Triagem Neonatal e atendimento a blocos de internação, cirúrgicos, unidade de terapia intensiva - UTI e centro de terapia intensiva - CTI. A unidade conta com um bloco voltado especificamente ao atendimento da população indígena de diversas etnias, respeitando sua cultura, especialmente no diz respeito à língua (com tradutores e intérpretes), alimentação e repouso. 


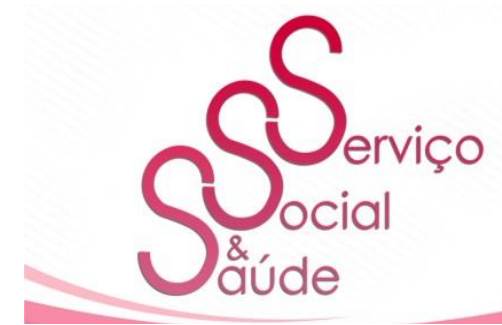

ISSN 2446-5992

(๑) $(0)$

doi: 10.20396/sss.v19i0.8665362

Das 25 assistentes sociais atuantes na Unidade de Saúde, somente 18 profissionais (72\%) aceitaram participar da pesquisa. Todas as entrevistadas são do sexo feminino, expressando a histórica feminização da profissão apontada por Cisne (2004; 2015) e Craveiro e Machado (2011).

Esse processo é resultante de uma sociedade patriarcal que institui hierarquicamente o que é trabalho/atividade de homens e de mulheres. Por isso, a divisão sexual do trabalho e todas as habilidades, qualidades e características a ela associadas como naturalmente pertencentes aos sexos, deve ser analisada como construção histórica com a nítida reprodução da desigualdade de gênero associada a interesses dominantes (CISNE, 2015, p. 49).

Para a realização desta pesquisa, foi solicitada autorização para a gestão da unidade hospitalar e assinada, pelas pesquisadoras, declaração de responsabilidade. Todas as profissionais entrevistadas tiveram acesso ao Termo de Confidencialidade - TC e Termo de Consentimento Livre e Esclarecido - TCLE. O questionário de entrevista foi dividido em quatro eixos: dados pessoais, formação profissional; atuação profisssional; saúde do trabalhador. A pesquisa foi submetida e obteve aprovação do Comitê de Ética em Pesquisa CEP, da Universidade Estadual de Roraima - UERR, sob Parecer nº 4.148.051.

Sobre o vínculo de trabalho, as 18 profissionais (100\%) são servidoras efetivas da Secretaria Municipal de Saúde de Boa Vista - RR e ingressaram na carreira a partir de concurso público de provas e títulos, o que pressupõe uma vinculação autônoma e protegida do trabalho e fortalece, entre outras coisas, a permanência nas funções, dificultando a rotatividade que poderia causar descontinuidade as ações. Estas condições, contudo, não afastam do serviço público os inúmeros possíveis impactos para a saúde dos trabalhadores, que muitas vezes atuam em ambientes considerados insalubres, sob intensa pressão e jornadas enfadonhas, assédio moral, salários defasados, ausência de reconhecimento das atribuições pelos gestores e distantes de possibilidades de desenvolvimento e ascensão nas carreiras.

Quando questionadas sobre o tempo de atuação na área da saúde, 8 profissionais (44\%) responderam de 1 a 5 anos, 6 profissionais (33\%) de 6 a 10 anos, 1 profissional (6\%) de 11 a 15 anos, 2 profissionais (11\%) mais de 15 anos e 1 profissional (6\%) não respondeu. 


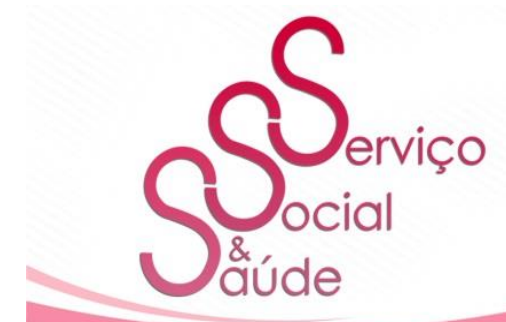

ISSN 2446-5992

(๑) $(0)$

doi: 10.20396/sss.v19i0.8665362

Inicialmente, é importante destacar que a questão aponta para o tempo de serviço na área da saúde, independente da atuação enquanto assistente social. Desta forma, se percebe que há profissionais que atuam há pouco mais de um ano -1 profissional (6\%) - e aquelas que atuam há mais de 15 anos - 2 profissionais (11\%) - não somente como assistentes sociais, mas também desempenhando outras funções.

Em relação ao tempo de atuação como assistente social na área da saúde, 8 (44\%) entrevistadas tem o tempo de trabalho entre um e cinco anos; 8 (44\%) atuam na saúde entre seis a dez anos; 1 profissional (6\%) atua entre onze a quinze anos e $1(6 \%)$ profissional possui mais de quinze anos de atuação neste campo. Esses dados devem ser considerados quando se analisa os impactos dos processos de trabalho na saúde dos trabalhadores: a permanência, por anos, em um ambiente de trabalho que as expõem às diversas situações de estresse e cansaço (físico e/ou mental) podem influenciar diretamente na qualidade da saúde do trabalhador. Esse debate pode ser observado no estudo desenvolvido por Faermann e Mello (2016), quando as autoras discutem a relação entre os processos de trabalho e o adoecimento dos/as assistentes sociais.

Com o objetivo de compreender se a dupla jornada de trabalho interfere na qualidade de vida do trabalhador, a pesquisa de campo verificou que 10 profissionais (56\%) possuem um único vínculo de emprego - apesar disso, algumas profissionais expressaram o anseio por um segundo vínculo - enquanto 8 profissionais (44\%) afirmaram trabalhar em outra instituição.

A respeito das profissionais que apontaram o interesse por um segundo vínculo de trabalho, vale ressaltar as discussões desenvolvidas por Antunes (2015) sobre os processos de precarização e flexibilização do trabalho, assim como sobre a gênese do trabalhador "polivalente" no seio da sociedade capitalista moderna, o que faz com que a concorrência entre os trabalhadores se intensifique e a necessidade do e pelo trabalho se desloque para o centro da sociabilidade humana.

Tais elementos contribuem para a construção de uma conjuntura mistificada, onde impera a necessidade de venda da força de trabalho na tentativa de satisfazer as necessidades 


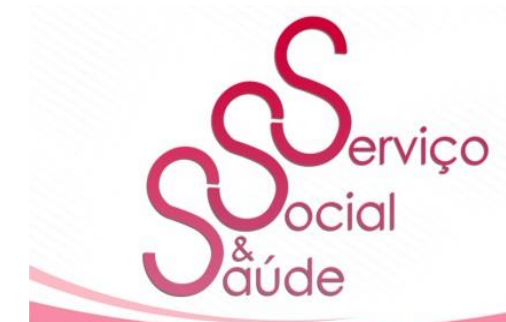

ISSN 2446-5992

$\Theta \odot \Theta \odot$

doi: $10.20396 /$ sss.v19i0.8665362

básicas do trabalhador e de sua família. Nesta esteira analítica, outras questões foram elaboradas com o objetivo de compreender o modo como as profissionais se veem na realização do trabalho diário e na instituição em que estão inseridas. Para tanto, na sequência, as profissionais foram questionadas sobre a percepção que possuem acerca da remuneração recebida a partir do trabalho realizado como assistentes sociais nesta unidade hospitalar.

Em relação à remuneração, 11 (61\%) assistentes sociais afirmaram ser bem remuneradas em comparação a outros espaços sócio-ocupacionais e considerando as demandas apresentadas, o espaço de trabalho, a valorização profissional, os recursos humanos e instrumentais, entre outros fatores que, segundo as entrevistadas, não se apresentam na realidade de muitas outras profissionais que atuam em distintas áreas.

Em contrapartida, há que se destacar que 7 profissionais (39\%) se consideram mal remuneradas pelo trabalho que desenvolvem. Nestes casos, se percebeu que a remuneração é um dos fatores de grande influência no aspecto individual e subjetivo da realização profissional e que tal elemento pode atuar como base para a gênese de sentimentos como o descontentamento, a insatisfação e a aflição. Além disso, o aspecto remuneratório apresentou bastante relevância quando relacionado a busca por outro emprego, já que 13 (72\%) assistentes sociais responderam que a necessidade de trabalhar mais decorre dos baixos salários percebidos, 5 (28\%) profissionais, optaram por permanecer em somente um vínculo.

Com base nesses dados, verificou-se que 10 (55\%) assistentes sociais possuem carga horária semanal igual a trinta horas; 7 (39\%) profissionais trabalham cerca de sessenta horas por semana e $1(6 \%)$ profissional trabalha mais de sessenta horas. No ato da pesquisa, se observou na fala das profissionais que, em casos específicos, a permanência nos locais de trabalho é mais frequente do que nos espaços do âmbito familiar ou que se apresentam no aspecto da vida particular de cada trabalhador.

Esta percepção traz para o centro da análise o debate desenvolvido por Antunes (2015) sobre o constante e intenso processo de internalização dos princípios e ideais capitalistas na vida fora do trabalho. Segundo o autor, o capital invadiu os espaços da vida do trabalhador, 


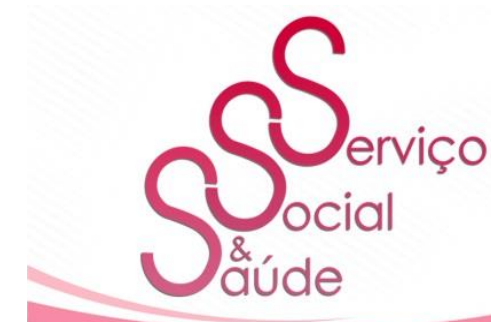

ISSN 2446-5992

(c) (1) (2)

doi: 10.20396/sss.v19i0.8665362

inclusive aqueles de caráter particular e transferiu para a sua subjetividade a necessidade ímpar do trabalho - o que torna o trabalhador refém dos ditames do capital.

Voltando a análise para o aspecto subjetivo, foi questionado às profissionais sobre o reconhecimento profissional por parte da instituição empregadora - considerando o trabalho na unidade hospitalar, uma vez que tais elementos são de grande importância não só para a construção da identidade do trabalhador, mas na forma como este considera o trabalho que realiza diariamente. A esta questão, 12 (67\%) assistentes sociais afirmaram que se sentem reconhecidas, tanto pela instituição, quanto pelos colegas de outras categorias profissionais (enfermeiros, técnicos de enfermagem, médicos, fisioterapeutas, psicólogos, fonoaudiólogos, entre outros). Todavia, 6 (33\%) profissionais afirmaram não se sentirem reconhecidas pela sua atuação.

Discutir sobre os aspectos subjetivos dos processos de trabalho é um debate de grande importância, fato destacado nos estudos e pesquisas realizadas pela Associação Nacional de Medicina do Trabalho - ANAMT (ASSOCIAÇÃO, 2017, on-line), principalmente no que se refere à valorização das potencialidades e subjetividades dos trabalhadores para a garantia da saúde. Faermann e Mello (2016) reafirmam a importância do debate acerca da relação saúdetrabalho, na perspectiva da valorização da subjetividade do trabalhador principalmente porque, segundo as autoras, o não reconhecimento das ações realizadas no ambiente de trabalho pode também colaborar para o sofrimento e o adoecimento da classe trabalhadora.

Em seguida, foi perguntado às profissionais sobre quais as demandas, entre as mais diversas que se apresentam cotidianamente, são consideradas mais complexas ou de difícil resolução. Destarte, se destaca que as respostas são diversas, uma vez que se considera a perspectiva particular de cada profissional acerca da questão proposta. Salienta-se, ademais, que considerar os elementos apontados pelas profissionais é de grande importância para conhecer a perspectiva das profissionais em relação ao trabalho e torná-las efetivas participantes do debate, contribuindo para o chamamento a uma discussão coletiva e ativa sobre um tema que estrutura a realidade da classe trabalhadora em seus mais diversos segmentos. 


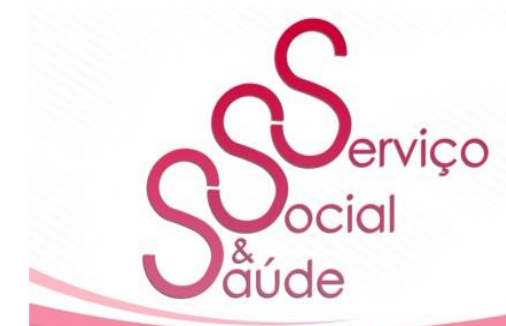

ISSN 2446-5992

(1) (0)

doi: $10.20396 /$ sss.v19i0.8665362

Além disso, cabe ressaltar que as demandas que se apresentam às profissionais variam em relação à complexidade e resolução, uma vez que a realidade se encontra em constante movimento dialético e que os usuários dos serviços prestados pela unidade hospitalar, são considerados agentes sociais com necessidades específicas.

É importante destacar que grande parte das profissionais apontaram mais de uma resposta para esta questão e, desta forma, considerou-se a quantidade de vezes em que cada demanda foi indicada pelas respectivas participantes.

Figura 1 - Demandas complexas e/ou de difícil resolução

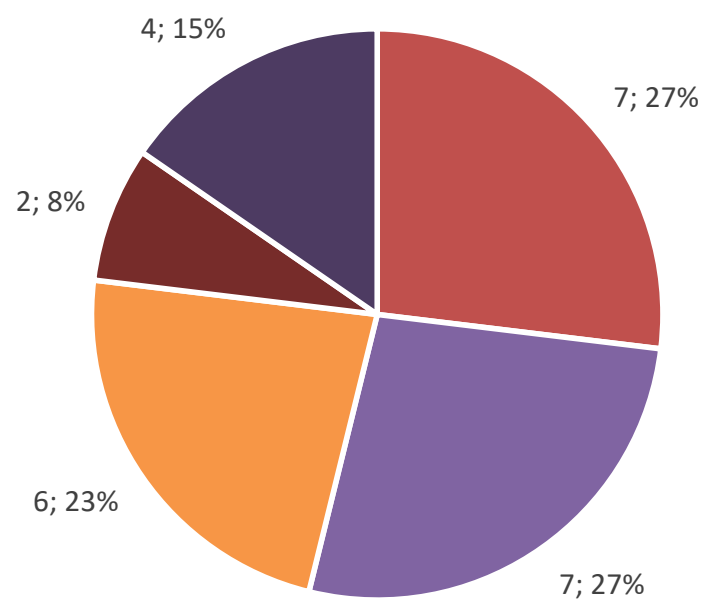

- Óbitos - Migrantes - Violência Sexual - Negligência - Espaço socio-ocupacional

Fonte: Pesquisa de campo. Elaboração própria.

O atendimento a situações que envolvem o óbito apareceu em 7 respostas, assim como as situações relacionadas aos processos migratórios - algumas profissionais anunciaram a limitação linguística como um dos maiores problemas, além da superlotação nos abrigos de refugiados, ausência de documentos pessoais dos imigrantes, as diversas questões que 


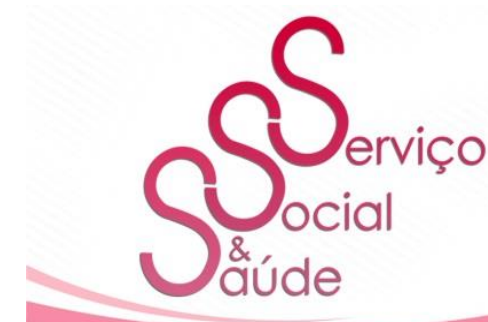

ISSN 2446-5992

(c) $10(2)$

doi: 10.20396/sss.v19i0.8665362

envolvem o trabalho da rede de proteção na referência e contrarreferência e os processos migratórios no estado de Roraima. $\mathrm{O}$ atendimento a situações que envolvem violência sexual esteve presente em 6 respostas como sendo a demanda mais complexa ou de difícil resolução e 2 respostas apresentaram a negligência familiar como um dos maiores desafios.

Por fim, 4 profissionais salientaram questões que envolvem a própria estrutura do espaço de trabalho - que não necessariamente são apresentadas pelos usuários - como a necessidade de deslocamento de alguns usuários, recursos humanos insuficientes, espaço de trabalho com estrutura inadequada, entre outros fatores.

A multiplicidade dos elementos apresentados demonstra a necessidade de discutir sobre o estresse ocupacional e os impactos na saúde do trabalhador, considerando também as assertivas apresentadas pelo próprio trabalhador como agente que executa, mas também sofre os impactos das ações realizadas. Além disso, cabe ressaltar que cada demanda exige determinado nível de esforço do trabalhador - físico, psicológico e emocional, fato que, atrelado a outros fatores, pode contribuir para a intensificação do estresse no ambiente de trabalho e, consequentemente, determina os impactos na saúde do trabalhador.

Nesse quadro, o trabalho profissional como assistente social (AS), enquanto uma das profissões que compõem o perfil de trabalhadores(as) dos serviços da seguridade social, situa-se entre a restrição e o atendimento às necessidades postas pelas manifestações da crise do capital e da questão social, as quais se tornaram mais acirradas, num contexto de restrição do acesso a essas políticas, garantidas em lei, mas, na realidade, quase sempre inexistentes. A dualidade: aumento da demanda e diminuição orçamentária dos serviços públicos, pode gerar a intensificação do trabalho e dificultar que as ações logrem êxito. Assim, no caso aqui relatado, AS que atuam na saúde podem enfrentar profundo desgaste biopsíquico ante a precarização dos serviços e o contato constante com demandas sensíveis que traduzem histórias de vida de crianças, adolescentes, mulheres, idosos e pessoas com deficiência, imersos em contextos de desemprego, subemprego, violências, doenças, drogadição etc. que exigem dos(as) profissionais respostas capazes de encontrar possíveis alternativas de ação, que garantam não apenas o direito às políticas sociais, mas $\mathrm{o}$ enfrentamento daqueles problemas (LOURENÇO et al., 2019, p. 155-156). 


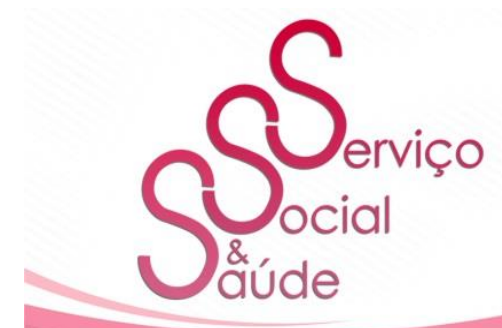

ISSN 2446-5992

(๑) $\odot \circ$

doi: $10.20396 /$ sss.v19i0.8665362

Sobre qualificação e aperfeiçoamento profissional, $15(83 \%)$ assistentes sociais entrevistadas possuem pós-graduação, enquanto 3 (17\%) possuem somente graduação; 61\% (11 profissionais) afirmaram sentir necessidade de realizar pesquisas em áreas específicas do trabalho cotidiano, como, por exemplo, sobre os processos migratórios e a violência sexual; $33 \%$ (6 profissionais) não sentem essa necessidade e $6 \%$ (1 profissional) não respondeu.

Iamamoto (2007), afirma que o enfrentamento do conservadorismo no serviço social requer uma postura profissional crítica e que atenda os preceitos da profissão, concebidos mediante uma luta coletiva e que reconhece a questão social como objeto de intervenção e investigação do serviço social. Nesse sentido, a autora aponta para a requisição de um perfil profissional

[...] culto, crítico e capaz de formular, recriar e avaliar propostas que apontem para a progressiva democratização das relações sociais. Exige-se, para tanto, compromisso ético-político com os valores democráticos e competências teórico-metodológica na teoria crítica em sua lógica de explicação da vida social. Esses elementos, aliados à pesquisa da realidade, possibilitam decifrar situações particulares com que se defronta o assistente social em seu trabalho, de modo a conectá-las aos processos sociais macroscópicos que as geram e as modificam. Mas, requisita também, um profissional versado no instrumento técnico-operativo, capaz de potencializar as ações de nível de assessoria, planejamento, negociação, pesquisa e ação direta, estimuladora da participação dos sujeitos sociais nas decisões que lhe dizem respeito, na defesa de seus direitos e no acesso aos meios de exercê-los (IAMAMOTO, 2007, p. 208).

Sobre o incentivo da unidade empregadora na qualificação profissional, 12 (72\%) profissionais afirmaram que o hospital não oferece os meios para qualificação no trabalho; 4 $(22 \%)$ profissionais responderam positivamente a esta questão e $1(6 \%)$ profissional disse que algumas vezes a unidade apresenta a possibilidade de capacitação no trabalho. Em todas as vezes, os custos para participação em cursos, oficinas e eventos ficam a cargo das profissionais, o que acaba por representar mais uma dificuldade para quem pretende se qualificar.

Entre os diversos fatores que estruturam os processos de trabalho diário e que atuam na determinação da qualidade da saúde do trabalhador, cabe refletir também sobre as relações 


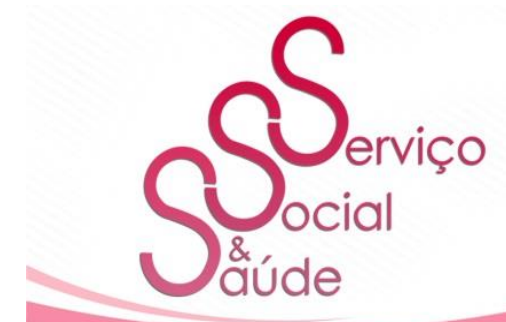

ISSN 2446-5992

(๑) (๑)

doi: $10.20396 /$ sss.v19i0.8665362

sociais estabelecidas no ambiente de trabalho. Com base nisso, foi elaborada uma questão voltada para a análise da existência de sobrecarga de demandas para o serviço social compreendido enquanto integrante de equipe multiprofissional. Entre as respostas apresentadas, 67\% (12 profissionais) responderam que há uma sobrecarga de trabalho por parte da equipe multiprofissional, através de demandas que não competem às assistentes sociais como, por exemplo, a disponibilização de vestuário, alimentação, cobertores, declaração de comparecimento e/ou atestados, entre outros; 28\% (5 profissionais) negaram que haja sobrecarga de trabalho, demonstrando a pluralidade de perspectivas de análise e 5\% (1 profissional) relatou que tais situações não se apresentam como realidade latente.

Tal aspecto é de grande valia, uma vez que representa uma importante luta da categoria profissional para a reafirmação e fortalecimento da identidade profissional, não apenas nos limites do mundo acadêmico, mas também nos contextos dos campos de atuação, onde, muitas vezes, vários elementos competem para a realização de uma atuação emancipada e consciente.

Com base na Resolução CFESS n 493/2006, questionou-se sobre as condições éticas e técnicas para o desenvolvimento do trabalho e 14 (78\%) profissionais afirmaram que a instituição não possui as condições estruturais e ergonômicas adequadas para a realização das atividades - elemento que atua como um dos fatores que contribuem para o fortalecimento do estresse no ambiente de trabalho; em contrapartida, 4 (22\%) assistentes sociais responderam positivamente a esta questão. A estrutura física está no topo das dificuldades percebidas, já que, segundo elas, o espaço físico é inadequado para abordagens individuais ou coletivas e isso acaba por influenciar na qualidade do serviço prestado, principalmente pela complexidade das demandas apresentadas diariamente e pela necessidade de garantir o sigilo das informações colhidas durante os atendimentos, o que fere frontalmente o Código de Ética da profissão.

Quando questionadas sobre a existência, na unidade, de atividades e estratégias voltadas a qualidade de vida e saúde do trabalhador, 14 (78\%) profissionais indicaram a inexistência de projetos ou ações, 3 (17\%) profissionais responderam que estas existem, mas 


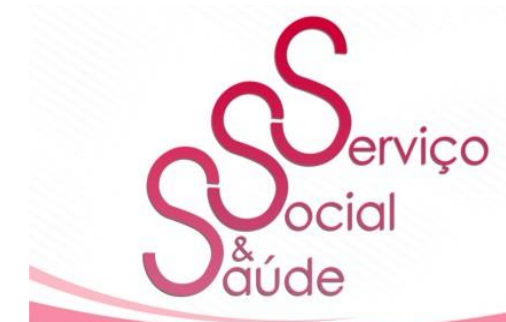

ISSN 2446-5992

(๑) $\odot \circ$

doi: $10.20396 /$ sss.v19i0.8665362

não souberam explicitá-las e $1(5 \%)$ profissional não respondeu. $\mathrm{Na}$ possibilidade da existência de projetos institucionais e do não reconhecimento destes por parte das profissionais, eleva-se, então, a importância e a necessidade da ampla divulgação entre os profissionais que compõem a equipe multiprofissional sobre as ações desenvolvidas na instituição.

Ainda sobre esse aspecto, 11 (61\%) assistentes sociais não consideram a instituição aberta a inovações no ambiente de trabalho. Em contrapartida, 5 (28\%) profissionais afirmaram que a instituição recebe propostas dos profissionais com o objetivo de discutir sobre a relação saúde-trabalho e promover ações de caráter preventivo. Além disso, 1 (5,5\%) profissional respondeu que "as vezes" a instituição se propõe a receber as propostas e 1 $(5,5 \%)$ entrevistada optou por não responder à questão.

Com o objetivo de compreender os efeitos subjetivos da realização do trabalho, se questionou às assistentes sociais sobre a forma como estas consideram a realização do trabalho diário, uma vez que se acredita, e os estudos apontam, que a realização no e para o trabalho são elementos de grande importância e que influenciam consideravelmente na integridade emocional e psicológica do trabalhador. Entre as respostas, 8 (44\%) profissionais consideram a realização do trabalho uma atividade prazerosa - fato que, segundo algumas entrevistadas, contribui para a realização profissional, enquanto $5(28 \%)$ vislumbram o trabalho como um processo desgastante.

Ademais, 2 (11\%) assistentes sociais apontaram o trabalho como uma atividade dinâmica, ou seja, com demandas que agregam conhecimentos e experiências diárias de grande importância para as profissionais; 1 (6\%) profissional considerou a realização do trabalho como ação monótona e $2(11 \%)$ profissionais indicaram outros posicionamentos. Estes dados expõe uma realidade que resume o elemento central desta análise: a percepção das profissionais com relação aos processos de trabalho, a significação que estes possuem e os impactos causados na saúde do trabalhador que se constituem como questões que devem ser transformadas em objeto de debate e intervenção prática. 


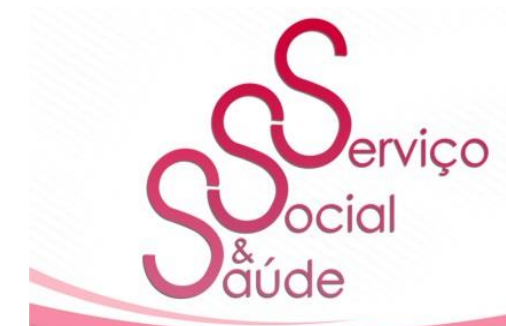

ISSN 2446-5992

(๑⿻)

doi: $10.20396 /$ sss.v19i0.8665362

Figura 2 - Percepção sobre o cotidiano do trabalho

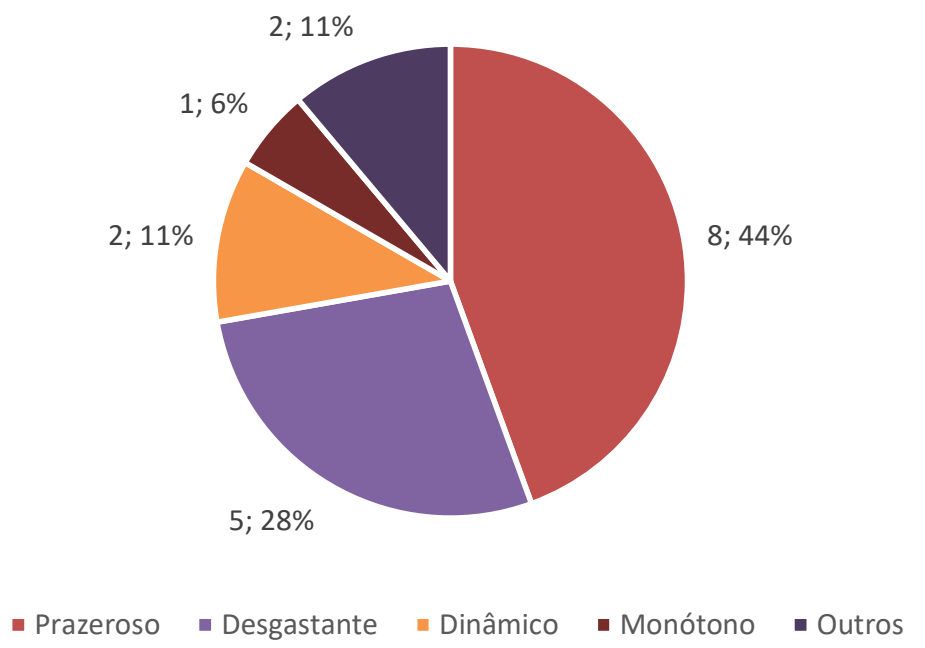

Fonte: Pesquisa de campo. Elaboração própria.

Quanto à satisfação profissional, 4 (22\%) profissionais se consideram muito satisfeitas com o trabalho que desempenham no hospital; 12 (67\%) assistentes sociais sentem-se satisfeitas e $2(11 \%)$ estão pouco satisfeitas com a realização do trabalho. Evidente que muitos elementos podem cooperar para a construção particular dessas percepções, contudo, é importante ressaltar que os aspectos subjetivos e que remetem à valorização das potencialidades humanas, exercem influência na saúde do trabalhador (ASSOCIAÇÃO..., 2017).

Fundamentado nesta perspectiva de análise, questionou-se se as profissionais tinham conhecimento do debate acerca do estresse ocupacional e a saúde do trabalhador. As 18 $(100 \%)$ participantes responderam positivamente a esta questão.

O conceito de estresse, originalmente utilizado na Física para descrever uma força ou um conjunto de forças que, aplicadas a um corpo, tendem a desgastá-lo ou deformá-lo, foi estudado por Selye considerando-se as reações desencadeadas pelo organismo exposto a diferentes situações nocivas à 


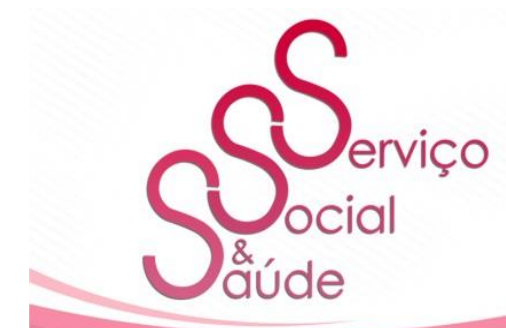

ISSN 2446-5992

(c) (1) (3)

doi: 10.20396/sss.v19i0.8665362

saúde. Os resultados mostraram que o estresse é caracterizado por uma síndrome específica de fatos biológicos, apresentando-se como uma resposta inespecífica do corpo diante de exigências às quais está sendo submetido, manifestando-se de forma positiva (eustresse), que motiva e provoca a resposta adequada aos estímulos estressores, ou negativa (distresse), que intimida o indivíduo diante de situação ameaçadora, com predominância de emoções de ansiedade, medo, tristeza e raiva (PRADO, 2016. p. 286).

Figura 3 - Satisfação profissional das assistentes sociais da unidade hospitalar

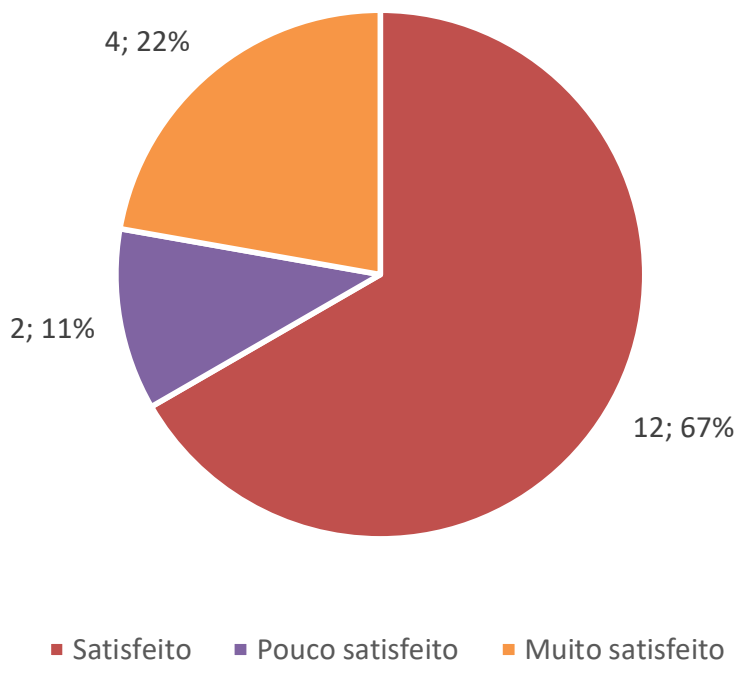

Fonte: Pesquisa de campo. Elaboração própria.

Desta forma, se verifica que nas vivências diárias sempre existirão fontes de estresse e que este, por sua vez, pode se manifestar de forma positiva ou negativa. Contudo, quando se discute sobre o estresse ocupacional, a análise é centralizada para os processos que ocorrem no interior do ambiente de trabalho e que podem ser nocivos à saúde do trabalhador.

Alguns componentes do trabalho - conteúdo, organização, ambiente, dentre outros - são reconhecidos como estressores e podem contribuir para o desenvolvimento do estresse ocupacional que se caracteriza como um padrão 


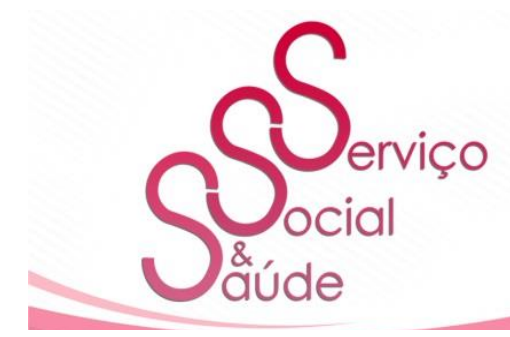

ISSN 2446-5992

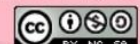

doi: 10.20396/sss.v19i0.8665362

de respostas fisiológicas, emocionais, cognitivas e comportamentais que enunciam a tensão e a angústia naqueles que têm dificuldade em enfrentar as demandas e pressões laborais incongruentes ao seu conhecimento e/ou habilidades (VERSA et al., 2012, p. 79).

A próxima questão buscou conhecer se as profissionais concordam com a afirmativa de que o ambiente e as rotinas de trabalho contribuem para o adoecimento mental das profissionais. Destas, 17 (94\%) profissionais concordam com a afirmativa enquanto 1 (6\%) assistente social discorda da afirmativa.

Sobre a utilização de estratégias para amenizar o estresse do ambiente de trabalho, 15 $(83 \%)$ profissionais afirmaram que realizam leituras sobre temas diversificados, atividade manual (crochê), de desenvolvimento interpessoal, entre outros. Em contrapartida, 3 (17\%) profissionais responderam que não utilizam nenhuma estratégia.

Em relação à percepção do trabalho de assistentes sociais na área saúde hospitalar como sendo ou não estressante, 9 (50\%) profissionais responderam que sim, consideram o trabalho estressante, 7 (39\%) profissionais não consideram o trabalho estressante e $2(11 \%)$ afirmaram que "talvez" o trabalho seja uma fonte de estresse - o que indica que esta não necessariamente é uma realidade latente. Ainda assim, 50\% (9 profissionais) afirmaram não buscar acompanhamento multiprofissional com regularidade quando se sentem ansiosos, deprimidos, exaustos etc. Outras $9(50 \%)$ profissionais responderam que procuram ajuda profissional. Dentre as especialidades procuradas, destacam-se com maior frequência: ginecologia, cardiologia, nutrição, otorrinolaringologia e endocrinologia. Formações voltadas à intervenção direta em saúde mental, como psiquiatria ou psicologia não foram citadas.

Considerando que a prática da atividade física é um fator determinante quando se discute sobre a qualidade de vida, 61\% (11 profissionais) das entrevistadas afirmaram não realizar exercícios físicos constantemente, enquanto 39\% (7 profissionais) afirmaram praticar exercício físico regularmente. Este dado é preocupante visto que "[...] os exercícios físicos podem ser grandes aliados no combate dessas tensões diárias. Além disso, a prática regular de atividades físicas melhora o condicionamento cardiovascular, evita a obesidade, o sedentarismo e uma série de doenças" (MINISTÉRIO..., 2013, s/p.). 


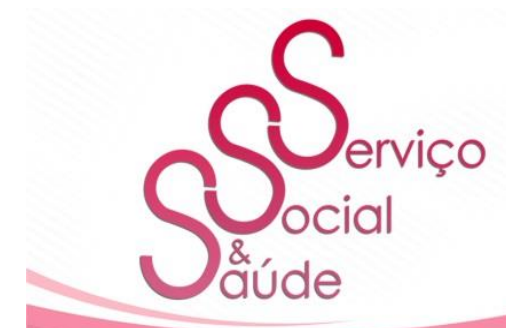

ISSN 2446-5992

(1) (0)

doi: $10.20396 /$ sss.v19i0.8665362

Normalmente as pessoas que trabalham sentadas, além de acumular energia e estresse, também podem sofrer com a fadiga devido ao esforço cognitivo da atividade laboral. Assim, podem chegar ao fim do dia sem disposição para as práticas corporais e atividades físicas. Os exercícios ajudam a melhorar a disposição no trabalho, além de melhorar a qualidade de vida dos praticantes, pois ocorre o fortalecimento das estruturas musculares e esqueléticas, evitando assim o sedentarismo e as doenças decorrentes e associadas (MINISTÉRIO..., 2013, s/p.).

Sobre os hábitos alimentares, 61\% (11 profissionais) afirmaram possuir hábitos alimentares saudáveis; no entanto, 39\% (7 profissionais) responderam negativamente a esta questão. Estudos desenvolvidos sobre esta temática, ressaltam de modo ainda mais intenso a importância em desenvolver hábitos alimentares saudáveis, considerando que os alimentos também podem auxiliar no combate ao estresse e na manutenção da qualidade da saúde.

Com base nas informações apresentadas até o presente momento, foi questionado às participantes se haviam algumas sugestões, por parte das profissionais, que pudessem ser desenvolvidas no ambiente de trabalho para garantir a saúde e a qualidade de vida do trabalhador. Cabe salientar que grande parte das profissionais destacaram mais de uma resposta para esta questão e, desta forma, considerou-se a quantidade de vezes em que cada demanda foi indicada pelas respectivas participantes.

Figura 4 - Investimentos em saúde do trabalhador

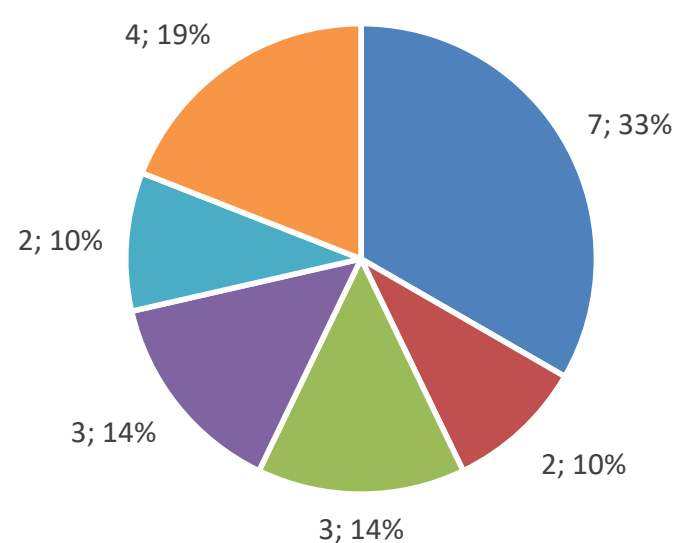

- Sala de relaxamento
- Melhores relações
interpessoais no trabalho
- Melhores condições
estruturais
- Outros
- Não responderam
- Não especificado

Fonte: Pesquisa de campo. Elaboração própria. 


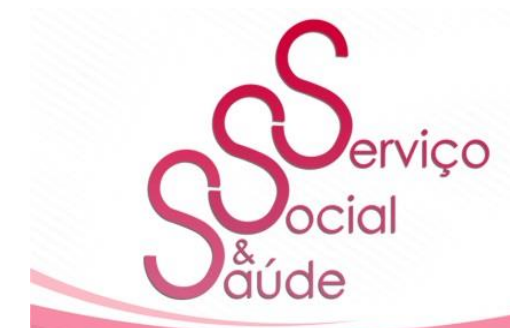

ISSN 2446-5992

(c) 10 (3)

doi: 10.20396/sss.v19i0.8665362

Em 7 respostas foi indica a criação de sala de relaxamento para os trabalhadores como uma estratégia eficiente para o combate ao estresse ocupacional no ambiente de trabalho; 2 respostas apostaram no desenvolvimento de melhores relações interpessoais no trabalho como fatores contribuintes para a manutenção da saúde; 3 respostas ressaltaram melhorias nas condições estruturais do ambiente de trabalho; para além destas, 3 profissionais apontaram, de forma genérica, para a necessidade do desenvolvimento de estratégias que promovam a saúde do trabalhador dentro da instituição e 4 assistentes sociais optaram por não responder a esta questão. Por fim, 2 profissionais indicaram outras conjunturas que, para fins desta análise, não foram especificados.

\section{Considerações}

As reflexões desenvolvidas a partir do referencial teórico e dos dados obtidos na pesquisa de campo realizada junto às assistentes sociais de uma unidade hospitalar de atendimento à criança demonstraram a importância em discutir a relação entre o estresse ocupacional e os impactos na saúde dos trabalhadores.

Nas análises e pesquisas que versam sobre a nova morfologia do trabalho é possível verificar a intensificação dos processos de precarização e flexibilização do trabalho que expõem, de forma cada vez mais intensa, os trabalhadores às mais diversas formas de exploração. Essas estruturas, bem como as experiências adquiridas durante a realização dos Estágios Supervisionados em Serviço Social I e II na unidade pesquisada, embasaram o desenvolvimento desta pesquisa e direcionaram a reflexão no sentido de compreender os processos de trabalho desenvolvidos no referido campo, considerando a perspectiva das profissionais e os impactos que estes processos causam na saúde das trabalhadoras.

Em nível internacional, o estresse é um dos principais fatores que levam ao adoecimento de milhares de trabalhadores. Parte desse processo surge a partir da intensificação da competitividade entre os trabalhadores, a constante demanda por produtividade, locais de trabalho com estruturas precarizadas, não-reconhecimento da atuação 


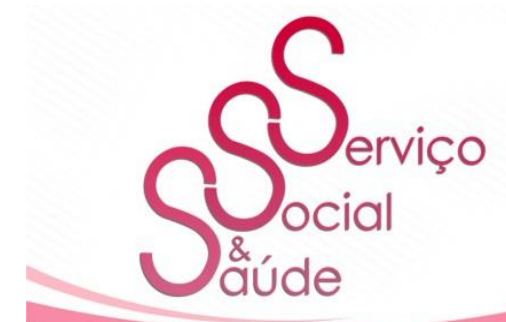

ISSN 2446-5992

(๑) (๑)

doi: $10.20396 /$ sss.v19i0.8665362

profissional, entre outros fatores. Tais processos apresentam consequências fisiológicas, psicológicas e comportamentais na saúde dos trabalhadores - que passam a desenvolver estratégias individuais na tentativa de evitar o adoecimento e, daí o destaque para a prevenção primária, ou seja, no ambiente em que se desenvolve o trabalho, por meio da identificação das estruturas que causam o adoecimento e do desenvolvimento das modificações necessárias com vistas a promover a qualidade da saúde do trabalhador.

Os dados colhidos a partir da pesquisa de campo subsidiaram a aproximação não somente com a realidade vivida pelas profissionais, mas também com a perspectiva particular que cada uma possui sobre as ações realizadas nos processos de trabalho. Além disso, demonstrou a diversidade de elementos que, segundo as participantes, integram a relação saúde-trabalho como, por exemplo, a valorização e reconhecimento profissional por parte da instituição, as relações interpessoais desenvolvidas com a equipe multiprofissional, as oportunidades de capacitação continuada no trabalho, estrutura de trabalho adequada, entre outros.

Como parte dos resultados alcançados a partir das reflexões ainda no período de realização do estágio supervisionado em serviço social, cabe ressaltar a realização de roda de conversa com as profissionais, no dia 20 de setembro de 2019, na brinquedoteca da unidade, com o objetivo de promover o autocuidado e o enfrentamento do estresse ocupacional no ambiente de trabalho. A atividade teve a participação de 2 educadores físicos que apresentaram um conjunto de atividades laborais que possam ser executados no ambiente de trabalho e que atuam no combate ao estresse e de uma profissional psicóloga do Centro de Referência de Saúde do Trabalhador - CEREST-RR, que contribuiu na análise sobre a importância dos cuidados com a saúde emocional e psicológica dos trabalhadores.

$\mathrm{Na}$ oportunidade, também foram divulgadas as informações levantadas durante as observações e realizados os devidos apontamentos e a entrega de portfólios de caráter educativo - como sugestão e a promoção de exercícios físicos para serem realizados no ambiente de trabalho, incentivo ao consumo de alimentos saudáveis, além de informações diversas sobre o estresse ocupacional. 


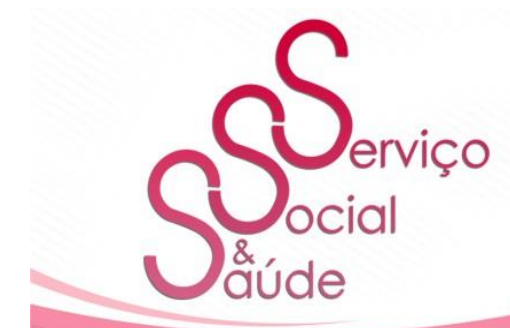

ISSN 2446-5992

(c) $10(0)$

doi: 10.20396/sss.v19i0.8665362

Por fim, vale ressaltar que o debate e a reflexão promovida na unidade hospitalar ultrapassaram as expectativas estabelecidas no início, uma vez que a ação alcançou vários outros profissionais que atuam na unidade como, por exemplo, enfermeiras/os, técnicos/as, porteiros, estagiários/as do Serviço Social - fato que contribuiu para a ampliação do debate e levou para as demais categorias profissionais uma temática de tamanha relevância, principalmente quando se considera a classe trabalhadora em sua completude, desviando da perspectiva analítica que "setorializa" os trabalhadores.

Ademais, a realização dessas atividades fortaleceu ações na instituição que buscavam promover o autocuidado dos/as trabalhadores/as, considerando que a atuação no hospital é diariamente envolvida por demandas com os mais diversos níveis de complexidade. Ou seja, esta é a confirmação de que os resultados ultrapassaram os limites da reflexão e alcançaram materialização objetiva, na promoção do "olhar para si" das profissionais, na perspectiva de que o estresse ocupacional é uma realidade latente e combatê-lo é necessidade vital para a classe que vive do trabalho, principalmente em tempos de supervalorização do capital em detrimento da desvalorização do trabalhador e seus direitos fundamentais.

Recebida em novembro de 2020 - Aprovada em novembro 2020

\section{Referências}

ANTUNES, R. Adeus trabalho? Ensaio sobre as metamorfoses e a centralidade do mundo do trabalho.16. ed. São Paulo: Cortez, 2015.

ASSOCIAÇÃO Nacional de Medicina do Trabalho. Transtorno mental é $3^{\text {a }}$ causa de afastamento de trabalho. São Paulo: ANAMT, 2017. Disponível em: <

https://www.anamt.org.br/portal/2017/10/26/transtorno-mental-e-a-3a-causa-de-afastamentosde-trabalho/>. Acesso: 19 jun. 2019.

BRASIL. Constituição da República Federativa do Brasil: Texto constitucional promulgado em 5 de outubro de 1988, com as alterações determinadas pelas Emendas 


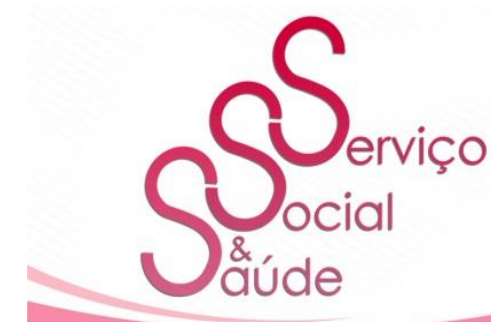

ISSN 2446-5992

(๑⿻)

doi: $10.20396 /$ sss.v19i0.8665362

Constitucionais de Revisão n ${ }^{\circ} 1$ a 6/94, pelas Emendas Constitucionais no ${ }^{\circ}$ 1/92 a 90/2015 e pelo Decreto Legislativo no 186/2008. Brasília/DF, 2015a.

BRASIL. Lei $\mathbf{n}^{\mathbf{0}} \mathbf{8 . 0 8 0}$, de 19 de setembro de 1990. Dispõe sobre as condições para a promoção, proteção e recuperação da saúde, a organização e o funcionamento dos serviços correspondentes e dá outras providências. Diário Oficial da União, Brasília, 19 set. 1990a. Disponível em: http://www.planalto.gov.br/ccivil_03/leis/L8080.htm. Acesso: 19 jun. 2019. BRASIL. Presidência da República. Lei Nº 8.662, de 7 de junho de 1993. Dispõe sobre a profissão de Assistente Social e dá outras providências. Disponível em: <http://www.cfess.org.br/arquivos/legislacao_lei_8662.pdf $>$. Acesso: 15 jun. 2020.

CISNE, M. Serviço Social: uma profissão de mulheres para mulheres? Uma análise crítica da categoria gênero na histórica "feminização" da profissão. Dissertação (Mestrado em Serviço Social) - Universidade Federal de Pernambuco. Recife, 2004.

CISNE, M. Gênero, divisão sexual do trabalho e Serviço Social. São Paulo: Outras Expressões, 2015.

CONSELHO Federal de Serviço Social. Resolução n 493, de 21 de agosto de 2006. Dispõe sobre as condições éticas e técnicas do exercício profissional do assistente social. Brasília: CFESS, 2006. Disponível em: 〈http://www.cfess.org.br/arquivos/Resolucao_493-06.pdf>. Acessado em 20 jan. 2020.

CONSELHO Federal de Serviço Social. Código de Ética do/a Assistente Social. Lei 8.662/93 de regulamentação da profissão. 10.ed. ver. e atual. Brasília: Conselho Federal de Serviço Social, 2012.

CRAVEIRO, A. V. MACHADO, J. G. do V. C. A predominância do sexo feminino na profissão do Serviço Social: uma discussão em torno desta questão. Anais II Simpósio

Gênero e Políticas Públicas. Universidade Estadual de Londrina, 18 e 19 de agosto de 2011. FAERMANN, L. A.; MELLO, C. C. V. de. As condições de trabalho dos assistentes sociais e suas implicações no processo de adoecimento dos profissionais. Textos \& Contextos, Porto Alegre, v. 15, n. 1, p. 96 - 113, julho, 2016.

IAMAMOTO, M. V. Serviço Social em tempo de capital fetiche: capital financeiro, trabalho e questão social. São Paulo: Cortez, 2007. 


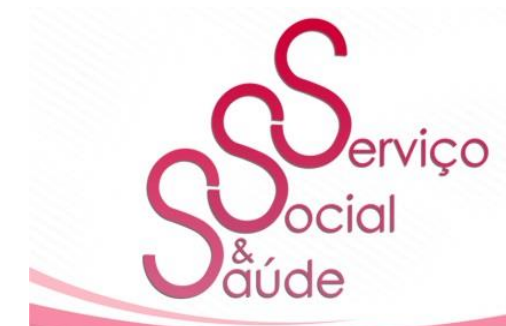

ISSN 2446-5992

(c) (1)(2)

doi: 10.20396/sss.v19i0.8665362

LOURENÇO, E; GOULART, P.; ANUNCIAÇÃO, L. LACAZ, F. A. de C. Condições de trabalho de assistentes sociais da área da saúde e repercussões psicossociais. Saúde Soc. São Paulo, v. 28, n. 1, p.154-168, 2019.

MINISTÉRIO da Saúde. Portaria no 1.823, de 23 de agosto de 2012. Institui a Política Nacional de Saúde do Trabalhador e da Trabalhadora. Disponível em: < http://bvsms.saude.gov.br/bvs/saudelegis/gm/2012/prt1823_23_08_2012.html>. Acesso em: 10 jan. 2020.

MINISTÉRIO da Saúde. Exercícios físicos podem ser ótimos remédios contra estresse e ansiedade. Blog da Saúde. Brasília: MS, 2013. Disponível em: <

http://www.blog.saude.gov.br/index.php/saudeemdia/33161-exercicios-fisicos-podem-serotimos-remedios-contra-estresse-e-ansiedade>. Acesso em: 20 ago. 2020.

PRADO, C. E. P. do. Estresse ocupacional: causas e consequências. Revista Brasileira de Medicina do Trabalho, 14 (3). São Paulo, 2016, p. 285-289.

RAICHELIS, Raquel. O assistente social como trabalhador assalariado: desafios frente às violações de seus direitos. Serv. Soc. Soc., São Paulo, n. 107, p. 420-

437, https://doi.org/10.1590/S0101-66282011000300003

REIS, A. L. P. P. dos; FERNANDES, S. R. P.; GOMES, A. F. Estresse e fatores psicossociais. Psicologia Ciência e Profissão, 30(4) Salvador, p. 712-725, 2010. VERSA, G. L. G. da S.; MURASSAKI, A. C. Y; INOUE, K. C.; MELO, W. A.; FALLER, J. W.; MATSUDA, L. M. Estresse ocupacional: avaliação de enfermeiros intensivistas que atuam no período noturno. Revista Gaúcha de Enfermagem, Porto Alegre, p. 78-85, 2012. 